\title{
ANÁLISE DA "CONVERSAÇÃO LITERÁRIA" NUM TEXTO DE GRACILIANO RAMOS
}

\author{
Dino Preti*
}

\begin{abstract}
RESUMO: Este texto procura definir as estratégias conversacionais usadas pelas personagens, no diálogo literário, para atingir seus objetivos na interação verbal, considerando-se as condições pragmáticas que cercam o diálogo construido. Um exemplo de um romance de Graciliano Ramos mostra as várias etapas que constituem uma teoria para a análise da "conversação literária".
\end{abstract}

PALAVRAS-CHAVE: Diálogo literário; estratégias conversacionais; variações lingüisticas; fatores pragmáticos na conversação.

\section{Considerações iniciais}

$\mathbb{E}$ ste texto se integra a um projeto iniciado na PUC/SP, com a participação de pós-graduandos, sobre o discurso construido, com base em textos da literatura brasileira.

Seus objetivos não são os de revelar como alguns de nossos prosadores realizaram o diálogo de suas personagens, com vistas a valorizar ou não suas obras, mas o de verificar como a língua escrita literária oferece exemplos expressivos de estratégias conversacionais que podem, às vezes, não ser encontrados na língua falada

* Pontifícia Universidade Católica de São Paulo - PUC-SP/Projeto NURC-SP (USP). 
PreTI, Dino. Análise da "conversação literária" num texto de Graciliano Ramos.

espontânea de todos os dias. A falta de naturalidade de certos textos gravados ou até a sua dificuldade em ser compreendidos contrasta freqüentemente com certos padrões ideais revelados pela "conversação literária", que poderiam até servir de modelos para a interação falada. (Cf. Tannen \& Lakoff, 1996: 139).

Por outro lado, a perfeita apresentação dos "traços de enunciação" (Cf. Urbano, 2000: 21), por parte do narrador, mostra-nos os elementos pragmáticos essenciais para a compreensão do diálogo construído, de uma forma, às vezes, não perceptivel a uma audiência, durante a realização de um diálogo espontâneo.

O texto literário aqui é encarado enquanto apenas corpus e seu estudo substituiria o exame de uma fita de gravação. Sua escolha é aleatória e, neste caso, servimo-nos de um segmento de um capítulo do romance Angústia, de Graciliano Ramos, publicado em 1936.

\section{Texto de apoio}

(Luís, trinta e cinco anos, funcionário público, "homem de ocupações marcadas pelo regulamento" tímido, encabulado diante das mulheres, feio, com seus "olhos baços, a boca muito grande, o nariz grosso", apaixona-se por Marina, sua vizinha de dezoito anos, "sujeitinha vermelhaça, de olhos azuis e cabelos tão amarelos que pareciam oxigenados", sensual, mas "frivola, incapaz de agarrar uma idéia", em quem reconhece "certas inclinações imbecis ou safadas”. Com intenção de casar-se rapidamente, procura aproximarse da família da moça, D. Adélia e seu Ramalho, casal de condições muito pobres. A primeira, "senhora idosa, cheia de rugas, tranqüila, um pano amarrado à cabeça"; o segundo, "uma criatura seca por natureza e humilde por oficio".

Na cena que estudamos, é a primeira vez que Luis e D. Adélia se detêm para uma conversa mais longa. 
- Boa tarde, D. Adélia. Como vai a senhora?

- Assim, assim, respondeu a mãe de Marina encostando-se à janela para esconder a saia encardida. Hoje em dia, quem é que vai bem?

Agora eu conhecia mais ou menos D. Adélia, falava com ela, parava na calçada às vezes: " - Bom dia, boa tarde, sim senhora, como tem passado?" Conhecia também o marido, seu Ramalho, sujeito calado, sério, asmático, eletricista da Nordeste. Não gostava de mim, provavelmente por causa das minhas palestras com a filha. Quando estávamos entretidos, estourava ali por perto:

- Marina, venha lavar os pratos. Marina venha cuidar das panelas. Lugar de moça é na cozinha.

Ora se Marina lidava com pratos e panelas!

- Velho pau!

E continuava na prosa.

- Cuidado com o sereno, Marina.

- Se isto é coisa que se suporte!

Seu Ramalho era uma criatura seca por natureza e humilde por oficio. Tinha um sorriso franzido, um ombro alto e outro baixo. D. Adélia, bamba, a voz sumida, os olhos assustados, parecia viver escondendo-se. Agora estava resolvida a conversar. Seria a respeito do meu namoro com Marina? Suspirou, mexeu os beiços, tornou a suspirar:

- Tudo pela hora da morte, seu Luís.

- É verdade, tudo pela hora da morte, D. Adélia. A senhora já reparou nos preços dos remédios? A farmácia tem uma goela!

D. Adélia fez um gesto de desalento:

- Nem me fale. A gente não pode adoecer mais não, seu Luís. 
PrETI, Dino. Análise da "conversação literária" num texto de Graciliano Ramos.

Ficamos um instante calados, olhando a rua, constrangidos. - Sim senhora, murmurei esfregando as mãos e sorrindo para o mulherão sardento.

- É isso mesmo, respondeu D. Adélia.

$\mathrm{E}$ depois de um silêncio comprido, enrolando as mãos no babado da roupa:

- Para sustentar uma casa a gente torce a orelha.

Concordei com alvoroço:

- Torce, D. Adélia. Que dúvida! Depois do dia vinte é preciso que uma pessoa se tranque para encurtar a despesa. Porque na rua é o café, o bilhete de teatro, a subscrição. Um horror.

- E o mercado, seu Luis! Quer chova, quer faça sol, é ali no duro. Ninguém pode passar sem comer.

- Perfeitamente, D. Adélia. Ninguém pode passar sem comer. E o pior é o aluguel da casa. O aluguel da casa, D. Adélia! Quanto paga a senhora pelo aluguel da casa?

- Cento e trinta mil réis. Um roubo.

- Eu pago cento e vinte. Um roubo maior, que aquilo não é casa. Uns quartinhos escuros, sujos. $\mathrm{E}$ tanto buraco de rato como nunca se viu. Uns ratinhos miúdos, deste tamanho, não sei se a senhora conhece, danados para roer pano. Não tenho um lenço inteiro, tudo furado.

- Aqui é o mesmo, declarou D. Adélia.

Deu um suspiro que elevou o peito volumoso, curvou-se mais para fora:

- Ó seu Luís, eu queria pedir-lhe um favor. Faz uma semana que estou matutando e sem coragem. Hoje botei a vergonha de banda. 
- Gue é que há, D. Adélia?

D. Adélia reeditou o suspiro:

- Estive pensando... Se o senhor puder, ouviu? Pedir não é desonra. A gente faz das tripas coração. Necessidade tem cara de herege.

- Diga, D. Adélia.

A vizinha baixou mais a voz, que tremia, e o carão sardento ficou encarnado como o vestido de chita:

- É por causa de Marina. Assim desocupada, com as mãos abanando... Ela não é preguiçosa. Cose, borda, mas trabalho de mulher em casa não adianta. Gasta-se tempo sem fim num bordado e recebe-se uma ninharia. Se fosse possivel arranjar um emprego para Marina...

Acendi um cigarro, pus-me a contar os paralelepípedos, sem me animar a desiludir a vizinha.

- Dê uma penada por ela.

Coitado de mim.

- Difícil. É preciso pistolão.

- Eu sei, disse D. Adélia. Foi por isso que me lembrei do senhor, que é bem relacionado. Só conhecemos o senhor.

- Mas, D. Adélia, respondi aflito, a senhora está enganada. Eu sou um infeliz, não tenho onde cair morto. Uma recomendação minha não serve. Mas vou tentar, ouviu?

Seu Ramalho dobrou o beco da usina elétrica e veio vindo, lento, negro de azeite e carvão.

- Boa tarde.

- Boa tarde, seu Ramalho. Como vai essa gordura? Estãvamos falando sobre a carestia. 
PRETr, Dino. Análise da "conversação literária" num texto de Graciliano Ramos.

Seu Ramalho estirou o beiço:

- Cada dia vai ficando pior. É de fazer um cristão endoidecer. Ora eu lhe conto.

Mas não contou nada. Costuma deixar as frases em meio.

- Pois é como lhe disse, murmurei. Vamos ver. Gue, para ser franco, nem sei se a Marina se ajeita. Ela sabe datilografia?

- Não sabe nada, atalhou seu Ramalho. Você foi amolar o rapaz com peditórios, mulher? Eu não tinha dito que não tocasse nisso?

- Que é que tem, seu Ramalho? Ela quer que a moça trabalhe. E natural.

- Trabalhar em quê, meu amigo? Só se for em pintar a cara, que é o que ela sabe fazer.

D. Adélia, vexada, continuava a enrolar os dedos trêmulos no vestido.

- Eu falei por falar. Se fosse possivel. Um ordenadozinho que desse para a roupa. Não há tantas moças empregadas? Nos telefones, , nos correios...

- São pessoas que sabem onde têm as ventas, criatura, interrompeu seu Ramalho. Ou que arranjaram proteção. E sua filha entrou na escola e saiu como entrou. Ou as escolas não prestam ou ela é bruta demais. Emprego para roupa. Tem graça. Cinqüenta mil réis de sapatos todos os meses. Não há dinheiro que chegue.

- O senhor é duro, seu Ramalho, arrisquei.

- Pois sim, respondeu o homem arquejando por causa da asma. É que vivo no toco, roendo um chifre.

Falava de cabeça baixa, os olhos no chão, os músculos da cara imóveis, a boca entreaberta, a voz branda, provavelmente pelo hábito de obedecer. 
- Eu falei por falar, gaguejou D. Adélia, caindo para uma ban$\mathrm{da}$, as banhas derramadas no parapeito da janela, onde fincava o cotovelo. Foi, a menina com as mãos abanando...

Seu Ramalho acendeu o cachimbo e pôs-se a esgaravatar as unhas com o fósforo queimado:

- É isso. Eu aqui não sei nada. Todo o mundo de rédea no pescoço. Casa de Gonçalo. As mulheres mandam, e o corno velho é o último que tem conhecimento das coisas. (Graciliano Ramos, Angústia, p. 48-51)

\section{A análise da "conversação literária"}

Ao examinarmos um diálogo construido devemos atentar para os seguintes aspectos:

1. o contexto histórico em que se realiza o diálogo, elemento indispensável para uma análise de textos distanciados no tempo, quando se torna mais dificil compreender problemas lingüísticos expressos no diálogo, ligados, por exemplo, a papéis sociais, formas de cortesia, expressões de tratamento etc. (Cf. Preti, 2000: 85-110); e o contexto geográfico que pode ser responsável pelas variações regionais da linguagem.

2. os fatores extralingüísticos e sua possivel ação sobre as personagens, considerando-se suas características socioculturais (grau de escolaridade, profissão, status etc.) ou psico-biológicas (faixa etária, gênero, tipo psicológico etc.) que podem, também, revelar variações da linguagem.

3. as informações trazidas pela situação de comunicação. São os elementos pragmáticos que precedem e acompanham as falas, mas também os traços de interatividade, durante o diálogo, como tratamentos gramaticais, expressões formulaicas, repetições, seqüências, interrupções sintáticas, sucessão dos turnos, marcadores conversacionais, silêncios etc. utilizados pelos 
"falantes" e que podem indicar proximidade/afastamento, clareza/ocultação/dissimulação, poder, conhecimentos partilhados etc.

4. as estratégias conversacionais empregadas pelos interlocutores, visando à obtenção de certos fins, e seus resultados ao longo do diálogo construído.

À primeira e segunda etapas que compõem essa metodologia poderiamos chamar de macroanálise da "conversação literária", em que nos orientamos pelas informações trazidas pela enunciação, mas também pelos conhecimentos pessoais do analista, porque, no caso da prosa escrita no passado, será necessário um conhecimento histórico-social, que, às vezes, o narrador não nos fornece.

À terceira e quarta etapas chamaríamos de microanálise, porque preponderam os elementos interacionais, que, muitas vezes, não dependem dos fatores extra-lingüísticos. Quer dizer, nem sempre o grau de escolaridade, o gênero, o status dos falantes justificarão seu comportamento no diálogo.

Um problema importante para quem analisa o diálogo construído sob esses enfoques puramente lingüísticos, deixando de lado, pois, a discussão sobre o valor literário dos textos (ou se eles representam uma aproximação maior ou menor com a fala espontânea, fato creditado como uma qualidade do autor, num outro tipo de análise), é encontrar um corpus que lhe permita obter todas as informações sobre a "conversação literária" que se realiza, como se o pesquisador fosse a audiência de um diálogo, no qual não toma parte, mas cuja situação de comunicação conhece em todos os pormenores: onde e quando e por que se realiza, quem são seus participantes, como interagem, como completam as falas com gestos (movimentos do corpo, direção do olhar etc.), alteração de ritmo de fala e altura de voz, para expressarem, por exemplo, humilhação, poder, intimidade, critica, rancor etc., além de refletirem as condições socioculturais e psico-biológicas. Essas informações, exterio- 
res ao diálogo propriamente dito, devem-lhe ser trazidas pelos elementos pragmáticos do texto, pelos traços da enunciação, já referidos.

\section{A macroanálise da "conversação literária"}

O segmento que analisamos descreve um diálogo possivelmente realizado dentro de um contexto histórico das primeiras décadas do século XX. Dele participam três personagens envolvidas, moradoras de Maceió. Não há diferenças históricas ou regionais importantes que possam interessar para a análise lingüística do texto.

A linguagem de Luís, enquanto personagem, reflete sua modesta condição cultural de um simples funcionário público. Mantém um distanciamento em relação a seus interlocutores, D. Adélia e seu Ramalho, uma relação de cortesia e respeito, expresso nas formas de tratamento o senhor/a senhora. Conforme veremos adiante, muito dessa atitude se deve a uma estratégia previamente determinada na conversação.

D. Adélia, mulher idosa, de pouca cultura, relegada aos afazeres domésticos, abusa das expressões formulaicas, o que é uma caracteristica dos falantes dessa faixa etária:

Tudo pela hora da morte.

A gente não pode mais adoecer.

A sustentar uma casa a gente torce a orelha.

Ninguêm pode passar sem comer.

Hoje botei a vergonha de banda.

Peđir não é desonra.

A gente faz das tripas coração. 
Preti, Dino. Análise da "conversação literária" num texto de Graciliano Ramos.

Necessidade tem cara de herege.

Trabalho de mulher em casa não adianta.

Essas fórmulas, em geral, indicam um falante de cultura modesta, que fala por lugares-comuns, facilmente compreensiveis e admitidos na sociedade em que vive. Os idosos têm propensão a conservar essas "verdades", que, às vezes, permanecem ao longo das gerações:

Os idosos e, particularmente, os "idosos velhos" têm facilidade em conservar em sua memória, com absoluta perfeição, frases-feitas, provérbios, refrões, expressões que, muitas vezes, remontam à sua infância. A melodia e a rima que, não raro, as acompanham, favorecem a permanência na memória. (Preti, 1991: 65-6)

O conteúdo das expressões formulaicas é, em geral, de natureza genérica e traz verdades admitidas pela sabedoria popular:

As frases feitas são objetivas, diretas, de compreensão imediata, conclusivas. Sua construção lingüistica se reveste de extrema simplicidade, mas atende a certas necessidades definidas de linguagem. Originárias da linguagem oral, as frases feitas são muito utilizadas pelos falantes de uma língua, nas situações da vida cotidiana, porque, em poucas palavras, são capazes de transmitir conceitos que demorariam a ser explicados. Além de serem portadoras de expressividade, as frases feitas representam uma economia de tempo na comunicação, já que os membros de uma comunidade possuem um certo estoque dessas expressões em sua memória e podem reconhecêlas rapidamente e atribuir-lhes sentido. (Salomão, 2001: 141)

Na conversação, as expressões formulaicas podem constituir um importante índice do conhecimento partilhado pelos falantes, com importante papel interativo, conforme veremos adiante.

Por outro lado, a figura de D. Adélia retratada no diálogo, faz lembrar o restrito papel social da mulher na sociedade brasileira de 
princípios do século passado, com sua cultura incipiente, pouco critica. Nas relações do dia-a-dia, seu papel é inferior ao do homem e costuma submeter-se às opiniões dele, nos diálogos familiares. Por isso, talvez, ainda hoje, afirma-se que "as conversações são microcosmos em que a opressão das mulheres pelos homens se realiza e perpetua", como acontece na sociedade norte-americana, segundo lembram West e Zimmerman, citados por Murray (1988). Da mesma maneira, Tannen (1996: 22), discutindo a relação entre gênero e discurso, lembra o argumento (que depois discute com maior amplitude) de que às mulheres, na conversação, cabe a condição de ouvintes, enquanto os homens agem como expositores.

No texto em análise não hả propriamente uma oposição absoluta ouvinte/expositor, com relação ao gênero dos interlocutores, porque, quando ocorre uma discussão sobre o problema do emprego para Marina, seu Ramalho, embora dê a última palavra em relação ao problema, fazendo calar a mulher, envergonhando-a pelo pedido feito a Luís, não tem capacidade de argumentar, pois, segundo nos informa a voz narrativa, ele não dá seqüência ao que fala ("Não contou nada. Costuma deixar as frases em meio.").

Ainda assim, as relações de poder, no ambiente do modesto casal, são bem expressas no diálogo pelas formas nominais de tratamento pouco respeitosas (mulher, criatura) que seu Ramalho dirige à D. Adélia; ou por meio de suas admoestações à mulher ("Eu não tinha dito que não tocasse no assunto?"), fazendo-a participar da culpa da filha ("E sua filha entrou na escola e saiu como entrou").

Seu Ramalho nos é apresentado como um homem humilde, que se julga inferiorizado, fala de cabeça baixa, "os olhos no chão, os músculos da cara imóveis, a boca entreaberta, a voz branda, provavelmente pelo hábito de obedecer". Também ele usa abundantemente expressões formulaicas, lugares-comuns, produto igualmente de sua condição cultural modesta, de suas convicções, marcadas pelos preconceitos da sociedade brasileira, arraigados com o tempo: 
Lugar de moça é a cozinha.

É de fazer um cristão endoidecer.

Pessoas que sabem onde têm as ventas.

Vivo no toco, roendo um chifre.

Todo mundo de rédeas no pescoço.

Casa de Gonçalo.

As mulheres mandam.

O corno velho é o último que tem conhecimento das coisas.

Essas três personagens se envolvem numa conversação cujo desfecho é o reflexo de suas limitações culturais, mas também de sua humilde condição social, verdadeiros exemplos de "humilhados e ofendidos".

\section{A microanálise da "conversação literária"}

Embora o encontro entre Luís e D. Adélia se dê, aparentemente, por acaso, o desenvolvimento do diálogo vai-nos mostrar que ambos pretendiam conversar, embora por propósitos diferentes. Assim, podemos lembrar que todos os falantes, dependendo de seus interesses, desenvolvem habilidades de condução de seu discurso, que podem indicar até um planejamento, pelo menos inicial, no sentido de conduzir a conversação para uma determinada direção, de acordo com seus objetivos.

Muito já. se discutiu a propósito de certas diferenças entre fala e escrita (hoje consideradas como fazendo parte de um continuum), acentuando que uma de suas diferenças básicas é a de que a primeira seria não-planejada, ou como quer Koch (1992: 69), "localmente planejada, isto é, planejada e replanejada a cada novo lance do jogo".

Poderiamos afirmar, então, que esse primeiro momento de uma conversação poderia constituir-se também num lance inicial 
do processo de interação, em que temos planos para desenvolver nosso discurso, mas também expectativas do discurso que será desenvolvido pelo nosso interlocutor:

Um encontro entre pelo menos dois interlocutores gera expectativas muito diversificadas, as quais estão intimamente relacionadas ao contexto, às condições em que o encontro ocorre, ao conhecimento partilhado, às diferentes perspectivas que os interlocutores possuem. Em situações interativas, os interlocutores sempre têm expectativas prévias (às vezes, chegamos até a ensaiar o que vamos dizer, como vamos dizer, simulamos a resposta de nosso interlocutor; e quase sempre esses ensaios não servem para nada no momento real da interação). Por ter expectativas prévias, o falante sempre procura estratégias para fazer com que elas ocorram, bem como fica atento à reação do seu interlocutor. (Dionísio, 2001: 94)

O diálogo entre Luís e $\mathrm{D}$. Adélia tem duas seqüências bem distintas. A primeira constitui uma estratégia conversacional de ambos e consiste em sondar o interlocutor, tentar conduzir o diálogo com uma aparente naturalidade, que torne possivel entrar no tema de seu real interesse. Luís deseja aproximar-se de D. Adélia, para tentar conseguir seu apoio para o namoro com Marina. D. Adélia pretende conseguir um emprego para a filha.

A rigor, tudo o que conversam nessa primeira seqüência não tem qualquer interesse para o desenvolvimento do tema que têm em mente e para a própria conclusão do diálogo. Há uma violação expressa da "máxima de relevência" de Grice (1982) pois os falantes tratam de tudo o que não é relevante para o tema principal da conversação. Essa "falação" (para usarmos um termo de Humberto Eco) aparentemente sem importância, nos remete à função fática da linguagem, àqueles discursos fáticos indispensáveis para manter uma ligação constante entre os falantes. Na verdade "indispensáveis justamente porque mantêm em exercício a possibilidade de comunicação, para fins de outras e mais substanciais comunicações" (Eco, 1984: 225). 
Poderíamos considerar esse momento inicial como uma seqüência preparatória, para usarmos a denominação de McLaughin (1984). Embora mais longa, tem praticamente a mesma função de uma pré-seqüência, denominação dada por Marcuschi a uma unidade "cuja motivação é ou estabelecer a coesão discursiva ou preparar o terreno para outra seqüência, ou unidades que contêm uma asserção, como no caso de uma informação." (1996: 43).

A seqüência preparatória dessa conversação constitui, na verdade, uma estratégia conversacional bem definida por parte dos interlocutores. Luís, tentando ser simpático à mãe de Marina, não percebe que ela habilmente o conduz para o tema da carestia da vida, para finalmente fazer-lhe o pedido de emprego. São muito comuns nas conversações as seqüências preparatórias que, como as pré-seqüências, preparam as condições para um pedido. Marcuschi, apoiado em idéias de Sinclair e Couthard, afirma que as pré-seqüências (e o mesmo podemos dizer das seqüências preparatórias) "representam um frame, ou melhor, um quadro preparatório para um evento lingüístico posterior" (op. cit., p. 43). Em nosso texto, esse evento lingüístico é o pedido de emprego para Marina.

No encontro, depois do cordial cumprimento ("Boa tarde, D. Adélia. Como vai a senhora?"), Luís percebe que a mãe de Marina deseja conversar ('D. Adêlia, bamba, a voz sumida, os olhos assustados, parecia viver escondendo-se. Agora estava resolvida a conversar. Seria a respeito do meu namoro com Marina?"). D. Adélia começa sua estratégia discursiva, respondendo já dentro de seus interesses: apresentar a Luís suas dificuldades econômicas: "Assim, assim, respondeu a mãe de Marina encostando-se à janela para esconder a saia encardida. Hoje em dia, quem é que vai bem?" E segue com as suas queixas:

- Tudo pela hora da morte, seu Luís. 
- A gente não pode adoecer mais nạa,o, seu Luís.

- Para sustentar uma casa a gente torce a orelha.

- E o mercado, seu Luís! Quer chova, quer faça sol, é ali no duro. Ninguém pode passar sem comer.

No seu interesse de ganhar o apoio de D. Adélia para o seu caso com Marina, Luís reage a essas queixas com certa excitação, tentando ser agradável ("esfregando as mãos e sorrindo", "Concordei com alvoroço") e procurando manifestar solidariedade ("Perfeitamente, D. Adélia. Ninguém pode passar sem comer").

No início da conversação, devemos atentar também para os gestos e a postura dos interlocutores. D. Adélia identifica-se plenamente com sua condição humilde. Sua posição é bem descrita pelas informações da enunciação: "encostando-se à janela, para esconder a saia encardida"; "D. Adélia, bamba, voz sumida, olhos assustados, parecia viver escondendo-se". Seus movimentos denotam sua inferioridade, sua hesitação, seu medo: suspira, mexe os beiços, torna a suspirar, faz um gesto de desalento, enrola as mãos no babado da roupa, manifestando nervosismo. Até que, após outros suspiros, eleva o peito volumoso, curva-se para fora e manifesta o pedido:

- Ó seu Luís, eu queria pedir-lhe um favor. Faz uma semana que estou matutando e sem coragem. Hoje botei a vergonha de banda.

Podemos dizer que, a partir dessa frase, inicia-se a segunda seqüencia da conversação que determinaria seu tópico mais importante: a discussão em torno da figura de Marina e a possibilidade de um emprego, objetivo inicial de D. Adélia.

A enunciação nos informa as condições inseguras com que D. Adélia, afinal, faz seu pedido a Luís (voz mais baixa e trêmula, rosto enrubescido, como se fora dizer algo inconveniente). 
Pretr, Dino. Análise da "conversação literária" num texto de Graciliano Ramos.

Há uma linha argumentativa no discurso de D. Adélia. Embora simples, ela arma o seu pedido com pressupostos de que Luis, se quiser (e ele deve querer, pois está interessado em Marina) poderá atendê-la. Primeiramente, sua estratégia é desculpar-se, supor que o pedido só poderá ser aceito pelo vizinho se ele puder (mas adiante afirmará que Luís é "bem relacionado", portanto, fica implícito no pedido que ele poderá arranjar o emprego, se quiser). E, finalmente, lembra que, quando se quer, "a gente faz das tripas coração" para conseguir, o que implica uma certeza de D. Adélia: se Luís quiser, ele conseguirá o emprego para Marina. Além disso, ela não se vexa do pedido, porque a necessidade tudo desculpa:

- Estive pensando... Se o senhor puder, ouviu? Pedir não é desonra. A gente faz das tripas coração. Necessidade tem cara de herege.

Em seguida, D. Adélia desfila as qualidades da filha, argumentando que os serviços da mulher em casa não são reconhecidos, mais um estereótipo em favor de seu pedido.

Luís, surpreso com o pedido de D. Adélia e, agora, sabendo dos reais objetivos da conversa, guarda silêncio. D. Adélia reitera o pedido ("Dê uma penada por ela"). Luís começa a responder, argumentando pela necessidade de um "pistolão" para conseguir o emprego. D. Adélia insiste, manifestando a idéia de que ele é uma pessoa bem relacionada e a única em tal situação que a família conhece. Esse argumento aflige Luís, obriga-o a se descobrir, revelando sua real condição de pobreza, o desprestígio social de sua função pública, desconhecidos de sua vizinha. Essa revelação constitui uma invasão de sua privacidade e contribui para a perda da sua face, na interação:

- Mas D. Ádélia, respondi aflito, a senhora está enganada. Eu sou um infeliz, não tenho onde cair morto. Uma recomendação minha não serve. Mas vou tentar, ouviu? 
Com a chegada de seu Ramalho, Luís retoma o tema da carestia, mas, ainda uma vez, seu objetivo é tentar ganhar o apoio dos pais de Marina. Por isso, parece-lhe oportuno, depois que seu Ramalho reforça as queixas de $\mathrm{D}$. Adểlia sobre a carestia, voltar ao problema do emprego de Marina. Refazendo-se da situação anterior, começa por encontrar impedimentos a um possível emprego ("Vamos ver. Que, para ser franco, nem sei se a Marina se ajeita"). Seu argumento para salvar-se da responsabilidade é eficiente: "Ela sabe datilografia?". Luís sabe que Marina não tem qualificações para qualquer emprego. Mas a pergunta é uma estratégia para destruir o pedido de D. Adélia.

Sentindo-se humilhado pelo pedido da mulher, seu Ramalho desanda a desvalorizar a filha e a criticar a mulher. Luís refaz sua posição, tenta justificar a atitude de D. Adélia, mas a situação está perdida para ela, que tenta salvar sua face. Primeiro, envergonhada, tremendo, procura justificar-se:

- Eu falei por falar. Se fosse possivel. Um ordenadozinho que desse para a roupa. Não há tantas moças empregadas? Nos telefones, nos correios...

A explosão de seu Ramalho visa não apenas a criticar a indolência da filha, mas também a atribuir responsabilidade pelo fato à mulher (que chama com desprezo de "criatura").

- São pessoas que sabem onde têm as ventas, criatura, interrompeu seu Ramalho. Ou que arranjaram proteção. E sua filha entrou na escola e saiu como entrou.

Sua critica vai à ironia das palavras da mulher ("Emprego para roupa. Tem graça".), numa clara atitude de agressão.

D. Adélia se retrai, não tem condições sequer de falar. Gaguejando, não consegue completar as frases. Desmoralizada, é a sua vez de entregar a face na interação: 
PRETI, Dino. Análise da "conversação literária" num texto de Graciliano Ramos.

- Eu falei por falar, gaguejou D. Adélia, caindo para uma banda, as banhas derramadas no parapeito da janela, onde fincava o cotovelo. Foi, a menina com as mãos abanando...

Subitamente, a conversação cessa. Seu Ramalho é o último a falar e suas palavras são igualmente uma declaração de humilhação e perda da face na interação. Como a voz narrativa já explicara, costumava deixar as frases pela metade. É como se manifestasse pensamentos esparsos, aparentemente sem seqüência, mas cujas frases contêm toda uma análise de sua vida infeliz (a perda do controle da família, o desgosto pela indolência da filha, os desentendimentos, a trágica humildade, a desesperança):

- É isso. Eu aqui não sei nada. Todo o mundo de rédea no pescoço. Casa de Gonçalo. As mulheres mandam, e o corno velho é o jultimo que tem conhecimento das coisas.

Estabelecidas as estratégias interacionais desse diálogo, observamos que as personagens, levadas pelos seus interesses e objetivos mais imediatos, freqüentemente, mudam suas posições, com o objetivo de resguardar sua face e obter os fins desejados. Luís almeja o assentimento de D. Adélia para o seu namoro com Marina. Uma de suas estratégias discursivas é a repetição, confirmando entusiasticamente o que D. Adélia diz, para agradá-la:

- Tudo pela hora da morte, seu Luís.

- É verdade, tudo pela hora da morte, D. Adélia.

- Para sustentar uma casa a gente torce a orelha.

Concordei com alvoroço:

- Torce, D. Adélia. Que dúvida!

- Ninguém pode passar sem comer. 
- Perfeitamente, D. Adélia. Ninguém pode passar sem comer.

Depois, descobertas as intenções dela, tenta resguardar-se, reduzindo suas esperanças. Em seguida, refaz sua posição, procura justificá-la perante seu Ramalho, mas seus intentos são frustrados. D. Adélia arma toda uma seqüência preparatória, chega ao pedido, insiste, mas vê seus intentos frustrados pela intervenção de seu Ramalho e acaba desmoralizada. Seu Ramalho desabafa suas frustrações em cima da mulher, retrai-se com os comentários tímidos de Luís, mas acaba confessando-se um fracassado.

Um dos recursos mais empregados no diálogo das personagens são as expressões formulaicas, cujo conteúdo faz parte dos conhecimentos partilhados pelos três falantes. Sua presença na conversação constitui importante elemento interativo, dando força aos argumentos em momentos-chave da conversação, como, por exemplo, na justificativa do pedido de D. Adélia.

Pela voz narrativa ficamos sabendo das formas como as falas são ditas, acentuando informações importantes da conversação e do comportamento dos interlocutores. Assim, temeroso de perder o apoio de D. Adélia, Luís "murmura" suas críticas à competência de Marina; e "arrisca" um julgamento sobre o violento discurso de seu Ramalho contra a filha e a mulher. D. Adélia, nervosa pelo destempero do marido, "gagueja" desculpas para o seu pedido fracassado. Seu Ramalho, ao final, fala de cabeça baixa, os olhos no chão, a voz branda, para reconhecer seu fracasso.

\section{Considerações finais}

O diálogo construído por Graciliano Ramos, neste segmento de seu romance Angústia, revela-nos como o escritor, colocando em cena personagens de limitados recursos lingüísticos, consegue habilmente mostrar o desenvolvimento do processo interacional num 
Pretr, Dino. Análise da "conversação literária" num texto de Graciliano Ramos.

diálogo cujos reais objetivos não se mostram claros de início. Daí a inteligente sondagem dos dois falantes que discorrem sobre frivolidades, numa seqüência preparatória inteligentemente imaginada pelo autor. Quando os objetivos se revelam, o conflito acontece, os três destroem-se mutuamente e terminam em confissões que exprimem a realidade de suas vidas, marcadas pela miséria e desesperança.

Embora, aparentemente, se trate de uma conversação banal, na verdade, a intensidade dramática de suas várias seqüências, desembocando numa frustração geral, revela com perfeição três personalidades aparentemente distintas, mas unidas pelo mesmo sentimento de humilhação que algumas de suas falas, também banais, revelam: humilhação do funcionário reles, sem nenhum status social: "Eu sou um infeliz, não tenho onde cair morto"; humilhação da mulher miserável e insegura: "Eu falei por falar"; humilhação do operário pobre, que se apresenta "negro de azeite e carvão", e se julga um inútil'no ambiente familiar: "É isso. Eu aqui não sei nada".

\begin{abstract}
This text tries do define the conversational strategies used by characters in the literary dialogue, to reach theses aims in the oral interaction, taking into consideration the pragmatic condition which enclose the constructive dialogue. A exemple from Graciliano Ramos' romance is quoted to show the various stages which constitute a theory to the "literary conversation".
\end{abstract}

KEYWORDS: Literary dialogue; conversational strategies; linguistic variations; pragmatic factors in conversation. 


\section{BIBLIOGRAFIA}

\section{Lingüística}

Dionisio, A. P. Análise da conversação. In: Mussalim, F. \& Bentes, A. C. (Org.) Introdução à Lingüistica. São Paulo: Cortez, v. 2, p. 69-100.

Косн, I. V. (1992) A interação pela linguagem. São Paulo: Contexto.

Marcuschi, L. A. (1996) Análise da conversação. São Paulo: Ática.

McLaughin, M. L. (1984) Conversation: how talk is organized. California: SAGE.

MurRaY, S. (1988) The sound of simulteaneous speech, the meaning of interruption, Journal of Pragmatics (North-Holland), v. 12, p. 115-36.

Preti, D. (1991) A linguagem dos idosos. São Paulo: Contexto. . (2000). Papéis sociais e formas de tratamento em A ilustre casa de Ramires, de Eça de Queiroz. In: BerRinı, B. (Org.) Eça de Queiroz: A ilustre casa de Ramires. Cem anos. São Paulo: EDUC.

Salomão, M. do C. R. C. (2001) Os provérbios e as frases feitas no discurso jornalístico. São Paulo: PUC/SP. Dissertação de Mestrado (Língua Portuguesa), $198 \mathrm{p}$.

Tannen, D. (1996) Género y discurso. Trad. de Marco Aurélio Galmarini. Barcelona: Buenos Aires: Paidós.

TANnen, D. \& LAKoff, R. (1996) Estratégia conversacional en una teoria pragmática: el ejemplo de Secretos de um matrimonio. In: TANnEN, D. Género y discurso. Trad. de Marco Aurélio Galmarini. Barcelona: Buenos Aires: Paidós, p. 137-69.

URbano, H. (2000) Oralidade na literatura. São Paulo: Cortez.

\section{Literatura - Texto de apoio}

Ramos, G. (1947) Angústia, 3. ed. Rio de Janeiro: José Olympio. 